\title{
Prevalence of Thyroid Dysfunction Among Depression Patients in a Tertiary Care Centre
}

\author{
Bikram Kafle, ${ }^{1}$ Bikram Khadka, ${ }^{2}$ Mohan Lal Tiwari ${ }^{3}$ \\ 'Department of Psychiatry, Devdaha Medical College, Rupandehi, Nepal, ${ }^{2}$ Department of Biochemistry, Devdaha \\ Medical College, Rupandehi, Nepal, ${ }^{3}$ Department of Medicine, Devdaha Medical College.
}

\section{ABSTRACT}

Introduction: Patients with thyroid disorders are more prone to develop depressive symptoms and conversely depression may be accompanied by various subtle thyroid abnormalities. The aim of the study was to estimate the prevalence of thyroid dysfunction in depression.

Methods: This is a descriptive cross-sectional study conducted at Devdaha Medical College and Research Institute employing a simple random sampling technique during the period of August 2019-January 2020. The research was approved by the Ethical Committee of the Institutional Review Board of Devdaha Medical College and Research Institute. The protocol approval number is 009/019. Data analysis was done in Statistical Package for the Social Sciences (Version 23). Results were presented as frequencies and percentages where required.

Results: Among 263 patients with depression, 69 (26.2\%) had abnormal thyroid status with most common being subclinical hypothyroidism 32 (12.2\%), 13 (4.9\%) overt hypothyroidism and 7 (2.7\%) overt hyperthyroidism.

Conclusions: The prevalence of thyroid dysfunction is high among patients with depression. We recommend to conduct routine thyroid function tests for all the patients with depression.

Keywords: depression; hyperthyroidism; hypothyroidism.

\section{INTRODUCTION}

Thyroid dysfunction has been found to be associated with variety of neuropsychiatric disturbances, like depression, mania, acute psychosis, and cognitive disorders.1,2 Overt hypo and hyperthyroidism are associated with increased risk of depression. ${ }^{3}$ Commonly documented abnormalities are elevated thyroxine (fT4) levels, low tri-iodothyronine (fT3), blunted thyroid stimulating hormone (TSH) response to thyrotropinreleasing harmone stimulation, and loss of the nocturnal TSH rise. ${ }^{4}$ The annual incidence of hyperthyroidism was also higher in patients with depression than in general population. ${ }^{5}$
Few studies have examined the prevalence of thyroid dysfunction in major depressive patients in Nepal. In a Neplease study, prevalence of thyroid dysfunction in depressive patients, found that $21 \%$ of depressive patients had abnormal thyroid function tests. ${ }^{6}$

The aim of the study is to find out the prevalence of thyroid dysfunction in the newly diagnosed depressed

Correspondence: Dr. Bikram Kafle, Department of Psychiatry, Devdaha Medical college, Bhaluhi, Devdaha-8, Rupandehi. Email: bikram12kafle@gmail.com, Phone: +977-9857042799. 
patient.

\section{METHODS}

We conducted a descriptive cross-sectional study at Devdaha Medical College and Research Institute employing a simple random sampling technique during the period of August 2019-January 2020. The research was approved by the Ethical Committee of the Institutional Review Board of Devdaha Medical College and Research Institute. The protocol approval number is $009 / 019$. The sample size of the study was calculated taking reference to the previous published study which reported $22 \%$ prevalence of thyroid disorder among depressive patients ${ }^{7}$ using the formula,

$$
\begin{aligned}
& n=Z^{2} \times p(1-p) / e^{2} \\
& =(1.96)^{2} \times(0.22) \times(0.78) /(0.05)^{2} \\
& =263
\end{aligned}
$$

where,

$\mathrm{n}=$ sample size

$Z=1.96$ at $95 \% \mathrm{Cl}$.

$\mathrm{p}=$ prevalence of thyroid disorder among depressive patients $^{7}$

$e=$ margin of error $(5 \%)$

We enrolled 263 patients who attended the Psychiatry OPD of Devdaha Medical College and were diagnosed with depression.

Inclusion criteria were patients with age $>15$ and those who agreed to join the research. Exclusion criteria included those who were not able to give the information because of their severity, known thyroid disease in past, substance use, medical comorbidites like hypertension and diabetes and pregnant patients. A self designed structured proforma was devised to obtain the socio-demographic characteristics of the study population.

Depression was diagnosed by the Psychiatrist. Diagnosis and grading as mild, moderate and severe was done on the basis of ICD -10 DCR as developed by the division of Mental Health of the World Health Organisation (WHO, 1992). As a rating scale Hamilton Rating Scale for Depression (HAM-D) was used for comparision with the clinical diagnosis of depression.

Five milliliter of venous blood sample at 8:00 am (to avoid the influence of circadian rhythm) was collected in a gel tubes. Blood samples were centrifuged at 3000 RPM for 10 minutes for separation of serum and stored at -20 degree celsius till get analysed. Serum levels of free T3, free T4, and TSH were determined with Electro-Chemiluminescence technique. Patients with thyroid function tests (TFT) reports from only Devdaha Medical College Laboratory were included to avoid bias. The normal values were as follows: free T3: 2.30$4.20 \mathrm{pg} / \mathrm{ml}$; free T4: 0.89-1.76 ng/dl; TSH: 0.55-4.78 $\mathrm{microlU} / \mathrm{ml}$. Thyroid dysfunction was diagnosed by level of free T3, free T4 and TSH as follows. Subclinical hypothyroidism as normal fT3, normal fT4, and elevated TSH. Subclinical hyperthyroidism as normal fT3, normal fT4 and low TSH. Overt hypothyroidism as decreased fT3, decreased $\mathrm{fT} 4$, and elevated TSH, and Overt hyperthyroidism as elevated fT3, elevated fT4, and decreased TSH.

Data were analyzed using SPSS version 21 (Chicago, Illinois, USA). Descriptive analysis was performed and mean, median and standard deviation (SD) calculated. Data were explained in percentages.

\section{RESULTS}

Mean age of the patient was 38.29 \pm 14.24 SD. Majority $143(54.4 \%)$ of the patients were in age group 25 45. Out of total cases $164(62.4 \%)$ were female, 220 $(83.7 \%)$ were married, $107(40.7 \%)$ had completed their secondary level of schooling. Majority of the cases $111(42.2 \%)$ were homemaker. Regarding religion 246 (93.5\%) cases were Hindu (Table 1).

Table 1. Comparison of socio-demographic variables among normal and abnormal thyroid status patients. $\mathbf{n}=\mathbf{2 6 3}$

\begin{tabular}{|lllll|}
\hline Variables & & $\begin{array}{l}\text { Normal } \\
\text { status }\end{array}$ & $\begin{array}{c}\text { thyroid } \\
\text { Abnormal } \\
\text { status }\end{array}$ & $\begin{array}{c}\text { thyroid } \\
\text { Total } \mathbf{n}(\%)\end{array}$ \\
& $15-24$ & $36(13.68)$ & $8(3.04)$ & $44(16.7)$ \\
Age group (years) & $25-34$ & $64(24.33)$ & $13(4.94)$ & $77(29.3)$ \\
& $35-44$ & $47(17.87)$ & $19(7.22)$ & $65(25.1)$ \\
& $45-54$ & $20(7.60)$ & $124.56)$ & $32(12.2)$ \\
& $55-64$ & $18(6.84)$ & $11(4.18)$ & $11.0)$ \\
\hline
\end{tabular}


Kafle et al. Prevalence of Thyroid Dysfunction Among Depression Patients in a Tertiary Care Centre.

\begin{tabular}{|c|c|c|c|c|}
\hline \multirow{2}{*}{ Sex } & Male & 82 (31.17) & $17(6.46)$ & 99 (37.6) \\
\hline & Female & $112(42.58)$ & $52(19.77)$ & $164(62.4)$ \\
\hline \multirow{4}{*}{ Marital status } & Single & $24(9.12)$ & $6(2.28)$ & $30(11.4)$ \\
\hline & Married & $158(60.07)$ & $62(23.57)$ & $220(83.7)$ \\
\hline & Seprated /widow & $12(4.56)$ & $1(0.38)$ & $13(4.9)$ \\
\hline & Illiterate & $25(9.50)$ & $18(6.84)$ & $43(16.3)$ \\
\hline \multirow{4}{*}{ Educational status } & Primary & $23(8.74)$ & $16(6.08)$ & $39(14.8)$ \\
\hline & Secondary & $85(32.31)$ & $22(8.36)$ & $107(40.70$ \\
\hline & Intermediate & $39(14.82)$ & $10(3.80)$ & 49 (18.6) \\
\hline & University & $22(8.36)$ & $3(1.14)$ & $25(9.5)$ \\
\hline \multirow{3}{*}{ Religion } & Hindu & $181(68.82)$ & $65(24.71)$ & 146 (93.5) \\
\hline & Buddhist & $11(4.18)$ & $4(1.52)$ & $15(5.7)$ \\
\hline & Others & $2(0.76)$ & 0 & $2(0.8)$ \\
\hline \multirow{6}{*}{ Occupation } & Unemployed & $15(5.70)$ & $4(1.52)$ & $19(7.2)$ \\
\hline & Homemaker & $73(27.75)$ & $38(14.44)$ & $111(42.2)$ \\
\hline & Agriculture & $15(5.70)$ & $8(3.04)$ & $23(8.7)$ \\
\hline & Service & $56(21.29)$ & $9(3.42)$ & $65(24.7)$ \\
\hline & Business & $22(8.36)$ & $6(2.28)$ & $28(10.6)$ \\
\hline & Student & $13(4.94)$ & $4(1052)$ & $17(6.5)$ \\
\hline
\end{tabular}

According to ICD-10 DCR based diagnosis of depression, patients with moderate depression were predominant
$206(78.3 \%)$, followed by severe depression 44 (18.3\%) and mild depression 9 (3.4\%) (Table 2).

Table 2. Diagnosis of depression according to ICD-10 DCR and its association with thyroid status. $n=263$

\begin{tabular}{|lllll|}
\hline \multirow{2}{*}{ Diagnostic tool } & Types of depression & $\mathbf{n ~ ( \% )}$ & $\begin{array}{l}\text { Normal thyroid status } \\
\mathbf{n ~ ( \% ) ~}\end{array}$ & $\begin{array}{l}\text { Abnormal thyroid status } \\
\mathbf{n}(\%)\end{array}$ \\
\cline { 2 - 4 } & Mid depression & $9(3.4)$ & $7(2.66)$ & $2(0.76)$ \\
& Moderate depression & $206(78.3)$ & $154(58.54)$ & $52(19.77)$ \\
& Severe depression & $48(18.25)$ & $33(12.54)$ & $15(5.70)$ \\
\hline
\end{tabular}

Categorization of patients on basis of thyroid status was done which shows only $69(26.2 \%)$ of the depressed participants has had thyroid disorder of which Subclinical hypothyroidism was major thyroid disorder 32 (12.2\%) and Inappropriate TSH secretions $5(1.9 \%)$ was least (Table 3$)$.

\begin{tabular}{|c|c|}
\hline Status of thyroid & N (\%) \\
\hline Normal & $194(73.8)$ \\
\hline
\end{tabular}

\begin{tabular}{|ll|} 
Hypothyroidism & $13(4.9)$ \\
Subclinical hypothyroidism & $32(12.2)$ \\
Subclinical hyperthyroidism & $4(1.5)$ \\
Overt hyperthyroidism & $7(2.7)$ \\
Inappropriate TSH secretions & $5(1.9)$ \\
Secondary hypothyroidism & $8(3)$ \\
Total & $263(100)$ \\
\hline
\end{tabular}

The mean value of HDRS score was $23.04 \pm 7.65$ SD. Mean of $f$ T4 $1.27 \pm 0.55$ SD, $f$ T3 $2.88 \pm 1.06$ and median value of TSH was 2.34 (Table 4 ).

Table 4. Mean, median and SD of thyroid hormones and HDRS score.

\begin{tabular}{|llllll|}
\hline Descriptives & Age & TSH(mlU/ml) & $\mathbf{f ~ T 4 ( n g / d l )}$ & fT3(pg/ml) & HDRS score \\
Mean \pm SD & $38.29 \pm 14.24$ & $4.70 \pm 14.73$ & $1.27 \pm 0.55$ & $2.88 \pm 1.06$ & $23.04 \pm 7.65$ \\
Median & 35 & 2.34 & 1.23 & 2.69 & 21 \\
\hline
\end{tabular}


Kafle et al. Prevalence of Thyroid Dysfunction Among Depression Patients in a Tertiary Care Centre.

\section{DISCUSSION}

The prevalence of thyroid dysfunction among depressive patients was found high in this present study. Among 263 patients with depression, slightly more than one fourth $26.2 \%$ had abnormal thyroid status. This findings of our study is in accordance with the study conducted by Charnsil, Ojha, Das and Loosen which showed $22.1 \%, 21 \%, 19.34 \%$ and $25 \%$ respectively. ${ }^{6-9}$ It was seen that $4.9 \%$ of patient had overt hypothyroidism, $12.2 \%$ had subclinical hypothyroidism and $6.1 \%$ had hyperthyroidism. This is in concordance with study conducted in Nepal which showed $11.4 \%$ having subclinical hypothyroidism and $4.3 \%$ had overt hypothyroidism. ${ }^{6}$ Our findings differed with findings from other parts of the globe which showed lower prevalence of subclinical hypothyroidism. ${ }^{7,10}$

The mean age of our study participants was $38.29 \pm 14.24$. This can be explained by the fact that the common age group for depression is middle age with $50 \%$ occurring in the 20 to 50 years age group. We next analysed that there was a huge gender gap in depression of our study participants. More than half $62.4 \%$ of study population of this study were female. The more percentage of females with depression could be due to the prevalence of higher depression in female than male as well as some socioeconomic and family-related factors moderate the relationship between gender and depression. ${ }^{11}$ Community surveys of symptoms of anxiety and depression have generally shown female: male ratio of 2:1, a finding supported by the large scale epidemiological catchment area (ECA) survey carried on US. ${ }^{12}$

Other major findings of our study is that moderate depression is the most common type of depression with $78.3 \%$ of patients, while $18.3 \%$ patients had severe depression and $3.4 \%$ were found to suffer from mild depression. Such a huge difference in the prevalence of the type of depression can be explained by the fact that mildly depressed patient usually do not seek medical help while severely depressed people usually go to emergency for help. These findings of our study are in concordance with the prevailing literature that it is mainly the moderate depression that are mostly diagnosed in outpatient basis.

Similarly study conducted in Nepal showed that fT3 and fT4 levels were found to be significantly raised in the moderate depression compared to the healthy controls. ${ }^{8}$ This difference in results might be because the onset of thyroid dysfunction in our group may have differed from other's studies.

Our study has some notable strength. First it has explored a new area of hospital based study among depressed patients. Secondly, this study advices early detection of thyroid disorders among depressive patients for better health outcomes.

The limitation of our study was that it was a hospital based cross-sectional study with limited sample size so this limits the demonstration of the effects of the thyroid dysfunction had over the course of the severity of depression and cannot be generalized unless repeated in the community.

\section{CONCLUSIONS}

The outcome of the study indicates high prevalence of thyroid disorder among depressive patients. Findings of our study emphasize in routine evaluation of thyroid hormone in depressive patients. However, a population based nationwide survey is recommended to reflect the actual epidemiology of thyroid disorder among depressive patients in Nepal as no such studies has been carried out so far.

\section{Conflict of Interest: None.}

\section{REFRENCES}

1. Davis J, Tremont G. Neuropsychiatric aspects of hypothyroidism and treatment reversibility. Minerva Endocrinol. 2007;32(1):49-65. [PubMed |Full Text]

2. Ceresini G, Lauretani F, Maggio M, Ceda GP, Morganti S, Usberti E, et al. Thyroid function abnormalities and cognitive impairment in elderly people: results of the Invecchiare in Chianti study. J Am Geriatr Soc. 2009;57(1):89-93. [PubMed $|\underline{\text { Full Text }}| \underline{\text { DOI] }}$
3. Medici M, Direk N, Visser WE, Korevaar TI, Hofman A, Visser TJ, et al. Thyroid function within the normal range and the risk of depression: a population-based cohort study. J Clin Endocrinol Metab. 2014;99(4):1213-9. [PubMed| Full Text $\mid \underline{\text { DOI] }}$

4. Hage MP, Azar ST. The link between thyroid function and depression. J Thyroid Res. 2012;2012. [PubMed | Full $\underline{\text { Text }}$ DOI] 
5. Wu E-L, Chien I-C, Lin C-H, Chou Y-J, Chou P. Increased risk of hypothyroidism and hyperthyroidism in patients with major depressive disorder: a population-based study. J Psychosom Res. 2013;74(3):233-7. [PubMed | Full Text | DOI]

6. Ojha S, Dhungana S, Chapagain M, Tulachan P. Association of thyroid dysfunction with depression in a teaching hospital. J Nepal Health Res Counc. 2013 Jan;11(23):30-4. [PubMed | Full Text | DOI]

7. Charnsil C, Pilakanta S. Prevalence of Thyroid Dysfunction and Its Relationship with the severity of Major Depressive Disorder. Ann Psychiatry Ment Health. 2016;4(6):1081. [Full $\underline{\text { Text] }}$

8. Das B, Baral N, Shyangwa P, Toora B, Lamsal M. Altered serum levels of thyroxine, triiodothyroinine and thyroid stimulating hormone in patients with depression. Kathmandu Univ Med J. 2007;5(3):330-4. [PubMed | Full Text]
9. Loosen PT, Prange AJ. Serum thyrotropin response to thyrotropin-releasing hormone in psychiatric patients: a review. Am J Psychiatry. 1982. [PubMed | Full Text | DOI]

10. Chhetry M, Sapkota N, Ojha N, Thapa S, Pandey A. Association of Thyroid Dysfunction with Mood Disorders in an OPD setting. J Psychiatrists' Association of Nepal. 2014;3(1):23-8. [Full Text DOI]

11. Van de Velde S, Bracke P, Levecque K. Gender differences in depression in 23 European countries. Cross-national variation in the gender gap in depression. Soc Sci Med. 2010;71(2):305-13. [PubMed |DOI]

12. Weissman MM, Klerman GL. Sex differences and the epidemiology of depression. Arch Gen Psychiatry. 1977;34(1):98-111. [PubMed |DOI]

This work is licensed under a Creative Commons Attribution 4.0 International License. The images or other third party material in this article are included in the article's Creative Commons license, unless indicated otherwise in the credit line; if the material is not included under the Creative Commons license, users will need to obtain permission from the license holder to reproduce the material. To view a copy of this license, visit http://creativecommons.org/licenses/by/4.0/ 